\title{
The aging lung
}

This article was published in the following Dove Press journal:

Clinical Interventions in Aging

5 November 2013

Number of times this article has been viewed

Erin M Lowery'

Aleah L Brubaker ${ }^{2}$

Erica Kuhlmann'

Elizabeth J Kovacs ${ }^{3}$

'Division of Pulmonary and Critical Care Medicine, Department of Internal Medicine at Loyola University Medical Center, ${ }^{2}$ Loyola University Stritch School of Medicine, ${ }^{3}$ Department of Surgery, Loyola University Medical Center,

Maywood, IL, USA
Correspondence: Erin M Lowery Division of Pulmonary and Critical Care Medicine, Department of Internal Medicine at Loyola University Medical Center, 2160 S First Ave, Building 54, Room I3IA, Maywood, IL 60I53, USA Tel + I $708216046 \mid$

Fax +I 7082166839

Email elowery@lumc.edu
Abstract: There are many age-associated changes in the respiratory and pulmonary immune system. These changes include decreases in the volume of the thoracic cavity, reduced lung volumes, and alterations in the muscles that aid respiration. Muscle function on a cellular level in the aging population is less efficient. The elderly population has less pulmonary reserve, and cough strength is decreased in the elderly population due to anatomic changes and muscle atrophy. Clearance of particles from the lung through the mucociliary elevator is decreased and associated with ciliary dysfunction. Many complex changes in immunity with aging contribute to increased susceptibility to infections including a less robust immune response from both the innate and adaptive immune systems. Considering all of these age-related changes to the lungs, pulmonary disease has significant consequences for the aging population. Chronic lower respiratory tract disease is the third leading cause of death in people aged 65 years and older. With a large and growing aging population, it is critical to understand how the body changes with age and how this impacts the entire respiratory system. Understanding the aging process in the lung is necessary in order to provide optimal care to our aging population. This review focuses on the nonpathologic aging process in the lung, including structural changes, changes in muscle function, and pulmonary immunologic function, with special consideration of obstructive lung disease in the elderly.

Keywords: aging, lung, pulmonary immunology, COPD

\section{Introduction}

Pulmonary disease has significant consequences for the aging population. Chronic lower respiratory tract disease, defined as asthma, emphysema, chronic bronchitis, bronchiectasis, and chronic obstructive pulmonary disease (COPD), is the third leading cause of death in people aged 65 years and older. ${ }^{1}$ According to 2010 census data, $13 \%$ of the US population, or 40.3 million people, are older than age 65 , which is higher than any previous census. Additionally, the population is aging at an increasingly faster rate each year. Between 2000 and 2010, the population age 65 years and over increased by $15.1 \%$ compared to the total US population which only increased by $9.7 \% .^{2}$ With such a large and rapidly growing aging population it is critical to understand how the body changes with age and how this impacts the entire respiratory system. Understanding the aging process in the lungs is necessary in order to provide optimal care to our aging population.

\section{Structural and functional changes with age}

The structure of the thoracic cavity, which houses and protects the lungs, is vital for optimal lung function. Changes to the spine, muscles, and ribs over time with aging 
impact normal lung function. As people normally age, narrowing of the intervertebral disk spaces causes kyphosis or curvature of the spine. ${ }^{3}$ This curvature decreases the space between the ribs and creates a smaller chest cavity. ${ }^{4}$ While a small amount of anterior curvature or kyphosis of the thoracic spine is normal, an angle greater than $40^{\circ}$, which is the 95 th percentile of normal, is defined as hyperkyphosis. ${ }^{5,6}$ After age 40 , the kyphosis angle begins to increase more rapidly in women than men, from a mean of $43^{\circ}$ in women aged 55-60 years, to a mean of $52^{\circ}$ in women $76-80$ years of age..$^{5}$ The prevalence and incidence of hyperkyphosis is reported in older adults varying from approximately 20\%-40\% among both men and women. ${ }^{5,6}$ In a study of 55 nonsmoking women with variable degrees of thoracic kyphosis Lombardi et $\mathrm{al}^{7}$ found that with increasing vertebral angle there was a significant decline in the fraction of exhaled volume in 1 second $\left(\mathrm{FEV}_{1}\right)$ and vital capacity (VC) during spirometry testing. ${ }^{7}$ This effect was most significant once the kyphotic angle was over $55^{\circ}$. Culham et al hypothesized that this effect is not from a decrease in thoracic cavity size alone, but due to the rib space narrowing, which decreases the length of the intercostal muscles. ${ }^{8}$ The angle of the muscle fibers in relation to the ribs may also affect the efficiency and decrease the movement of the lower ribs during inspiration. ${ }^{8}$ These changes are structural and based on the origin and insertion of the muscles.

In addition to structural changes, there are changes in intrinsic function of the muscles with age. Overall muscle function in the body decreases by $2 \%$ annually as we age. ${ }^{9,10}$ Aging is associated with reduced inspiratory and expiratory respiratory muscle strength. ${ }^{11}$ Respiratory muscle decline can lead to an inability to ventilate in the face of increasing demands, such as that seen in respiratory disease. There is also evidence that at the cellular level, the muscles of elderly individuals have less mitochondrial adenosine triphosphate reserves to sustain a sudden increase in metabolic demand. ${ }^{12}$ If an elderly person becomes ill with pneumonia, and therefore has increased metabolic demands for oxygen in the setting of decreased respiratory muscle strength, decreased cellular energy reserve, and decreased overall muscle function, he or she may not be able to meet those demands. This leads to an increased risk of respiratory failure in older individuals. ${ }^{13}$

With aging there is a decreased ability to clear mucus from the lungs. Two mechanisms primarily contribute to this decline: 1) reduced cough strength and 2) alterations in the body's ability to clear particles in the airways. First, cough plays a vital role in clearing mucus from the airways.
Coughing is a maneuver that requires generation of a high forced expiratory flow. During a cough maneuver, inspiratory muscles contract to allow the lungs to take in a large tidal volume necessary to augment a sustained high expiratory flow. ${ }^{14}$ Next, the expiratory muscles contract to build high positive intrapleural and intraairway pressures for the development of peak expiratory flow rates. ${ }^{15}$ Finally, when the glottis is opened, the cough occurs, and the mucus is expelled from the airway into the mouth. Any decrease in the strength of the respiratory muscles will greatly impact an individual's ability to generate the force required for an effective cough. ${ }^{16}$ Aging is associated with both inspiratory and expiratory respiratory muscle strength reduction. ${ }^{11}$ Polkey et al showed a 13\% decrease in transdiaphragmatic pressure gradients, a surrogate for diaphragm strength, in older subjects (ages 67-81) as compared to younger subjects (ages 21-40). ${ }^{17}$ Tolep et al compared the maximum transdiaphragmatic pressure (Pdimax) obtained during voluntary maximal inspiratory efforts in nine young (19-28 years) and ten elderly (65-75 years) subjects and found that the average Pdimax of the elderly subjects $\left(128 \pm 9 \mathrm{~cm} \mathrm{H}_{2} \mathrm{O}\right)$ was significantly lower than the average Pdimax of the younger subjects $\left(171 \pm 8 \mathrm{~cm} \mathrm{H}_{2} \mathrm{O}\right) .{ }^{18}$ More specifically, there is age-related atrophy of muscle fibers, termed sarcopenia, which may also explain the reduced respiratory strength in the elderly. The decrease in muscle fiber strength can be as high as $20 \%$ by age $70 .{ }^{18-21}$ There are complex changes involving the mitochondria, muscle fiber disorganization, age-related muscle fiber transitions, and metabolic shifts in the aging muscle that can also explain the reduction in muscle strength. ${ }^{22}$

The mucociliary elevator refers to the action of ciliated cells along the upper and lower airway to beat in synchrony, trapping and clearing mucus and foreign particles out of the lungs. ${ }^{23}$ The upper airway nasal mucociliary cells work to remove large particles before they enter the smaller airways, and the lower airway mucociliary cells remove fine particles from the airway over a longer period of time. ${ }^{24}$ There are alterations in both the clearance of large and small particles with aging. De Oliveira-Maul et al used the clearance of saccharin that was inhaled through the nares of healthy subjects to measure large airway nasal mucociliary function. They demonstrated that in people over age 40, there was a delayed nasal mucociliary clearance time of saccharin compared to subjects under 40 years of age. ${ }^{25}$ Using radiolabeled particles that can travel past the upper airway and enter into the smaller airways in healthy nonsmoking subjects, Svartengren et al evaluated clearance of the labeled particles in different age groups ranging from age 19-81 years. They found that age 
alone was negatively associated with airway clearance of radiolabeled particles at $1,2,7,14$, and 21 days. ${ }^{26}$ The association between age and decreased clearance by the mucociliary elevator may be due to beat frequency of the cilia. The studies of beat frequency in cilia are confounded by the presence of cigarette smoking, which has a large impact on beat frequency. Age has not been a statistically significant predictor of decreased beat frequency. ${ }^{27}$ The impact of structure and functional changes created by the aging process is summed up in Figure 1.

\section{Aging and inflamm-aging}

In addition to these age-related structural changes in the lung, advanced age contributes to systemic immune dysfunction. Of particular interest is the basal activation of the innate immune system in aged individuals in the absence of an immunologic threat. ${ }^{28}$ This phenomenon, referred to as "inflamm-aging", is marked by elevated levels of tissue and circulating proinflammatory cytokines in aged subjects. ${ }^{28}$ Specifically, increased levels of interleukin (IL)-1 $\beta$, IL-6, and tumor necrosis factor- $\alpha$ (TNF- $\alpha$ ) have been observed in aging rodent and human studies. ${ }^{29-32}$ Theoretically, heightened levels of these cytokines in the absence of an immunologic threat or infectious target may be a contributory factor to reduced elasticity and destruction of the delicate lung parenchyma with advanced age. Related to inflamm-aging is the blunted immune response, known as "immunosenescence", following a pathogenic threat or tissue injury. ${ }^{28}$ Multiple studies have established reduced levels of mediators such as TNF- $\alpha$,

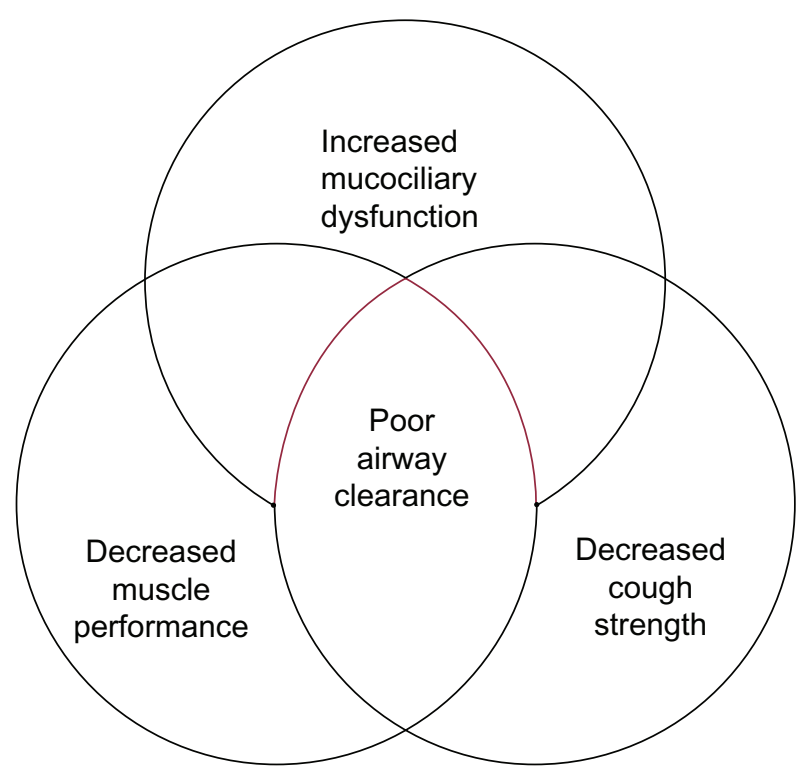

Figure I The physiologic changes in aging which place elderly patients at risk for poor airway clearance.
IL-6, interferon- $\gamma$, nitric oxide, monocyte chemoattractant protein-1, and macrophage inflammatory protein- $1 \alpha$ after different types of antigenic stimulation in aged animals..$^{33-38}$ This basal level of inflammation, for example, elevated levels of IL-6, has been suggested to contribute to this subsequent immunosenescence following an immune challenge. ${ }^{28,39}$ Using a model of IL-6 knockout mice, Gomez et al demonstrated restoration of cytokine production of IL-1 $\beta$, IL-12, and TNF- $\alpha$ following lipopolysaccharide (LPS) challenge in aged IL-6 knockout animals to levels comparable to young wild-type. ${ }^{40}$ These data suggest that the basal elevation of circulating IL-6 observed in aged wild-type animals prior to stimulation may contribute to the inability to upregulate cytokine production in the presence of an infectious threat as represented by LPS. ${ }^{40}$ In addition to these cytokine alterations with aging, more recent data demonstrate a role for microRNAs in inflamm-aging and cellular senescence. ${ }^{41}$ Specifically, microRNA 146a has been associated with a "senescent associated proinflammatory status" in the setting of vascular remodeling. ${ }^{42}$ Together, these data support the relationship between inflamm-aging and immunosenescence, suggesting that a disruption in the balance of pro- and anti-inflammatory mediators results in a baseline proinflammatory environment with advanced age that subsequently dampens an appropriate innate and adaptive immune response (Figure 2).

In addition to this reduced activation, there are data that support a shift in the temporal response to injury with aging, such that this initial immunosenescence over time results in a protracted immune response and chronic inflammation. ${ }^{43,44}$ These studies will be discussed in depth later in the context of pulmonary inflammation with aging; however, it is important to consider that this imbalance of immune mediators, delayed immune activation, and protracted course of inflammation may result in increased morbidity and mortality in aging individuals following infection, environmental exposures, or systemic injury. ${ }^{45-48}$

\section{Age and pulmonary immunity}

The lung has immunologic defenses that are both complex and resourceful, utilizing both an innate and adaptive immune response to inhaled antigens. Innate immunity is the critical first line of defense for the lungs. Adaptive immunity (acquired immunity) is antigen-specific and is required to ward off encapsulated bacteria, viruses, and intracellular pathogens. This form of immunity relies on immunologic memory and lymphocyte production of antibodies to nonself threats. Some important changes in the innate immunologic response occur with aging. Toll like receptors (TLRs) are key 


\section{The aging immune system}

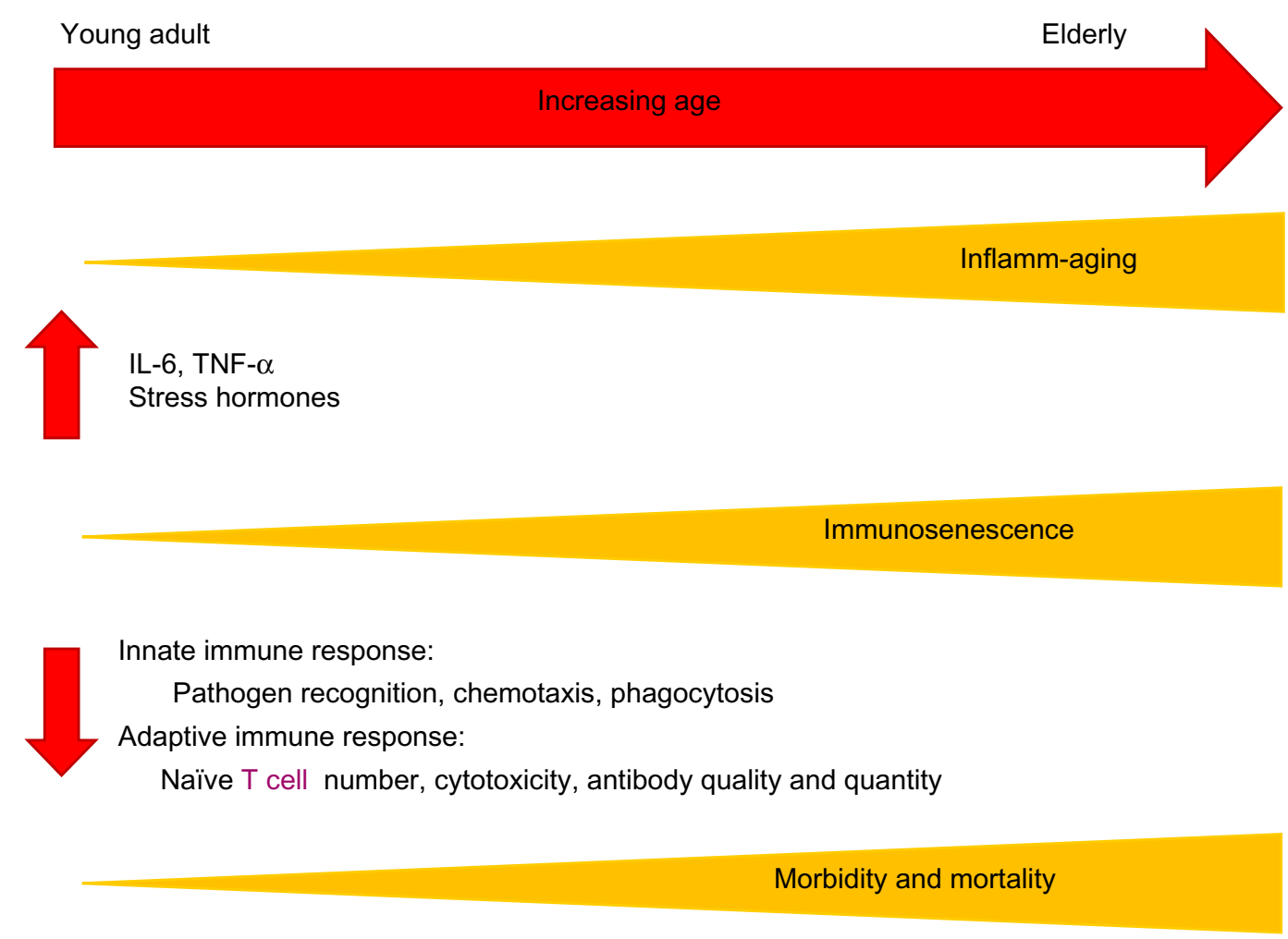

Figure 2 Increasing age leads to elevated basal levels of inflammation (inflamm-aging) and increased immunosenescence, which are associated with changes in both innate and adaptive immune responses, contributing to the heightened morbidity and mortality seen in the elderly.

Abbreviations: IL, interleukin; TNF, tumor necrosis factor.

molecules in recognition and initiation of the innate immune response. In the context of aging, there are conflicting data regarding the impact of age on murine and human expression of TLRs or downstream signaling mediators. ${ }^{38,49-51}$ While some of these murine studies on monocytes and macrophages report reduced expression of one or several TLRs, ${ }^{34,49}$ another report demonstrates alterations in downstream TLR signaling involving p36. ${ }^{51}$ Reduction in $\mathrm{p} 38$ signaling is supported by studies in human monocytes from aged subjects, where dampened p38 signaling was associated with diminished phosphorylation of $\mathrm{p} 38 .{ }^{37}$ Additionally, these authors observed a reduction in TLR1 but no changes in TLR2 expression. While the data are divergent on how aging impacts TLR expression, the data do suggest that alteration in the TLR pathways plays a role in an age-related aberrant initiation of the innate immune response and may contribute to an inability in rapidly recognizing and eradicating a pathogen. In studies of cigarette smoke exposure, elevated expression and nuclear translocation of nuclear factor- $\mathrm{k} \beta$ murine neutrophil chemokines, CXCL1 and CXCL2, were observed in aged mice. ${ }^{52}$ This was accompanied by a protracted neutrophilia in the lung parenchyma. ${ }^{52}$ Moreover, following exposure to environmental toxins such as diesel exhaust, the increased pulmonary neutrophilia in lung parenchyma led to congestion and delayed clearance in aged animals as compared to young mice. ${ }^{53}$ These data suggest that inhaled pollutants cause a prolonged, aberrant pulmonary immune response, which may translate into increased tissue damage, playing a part in environmental, age-related pathology like COPD. Pulmonary infection with Francisella tularensis in aged rodents demonstrated delayed production of neutrophil chemokines in conjunction with an attenuated neutrophil recruitment at early times points, ${ }^{43}$ supporting the concept of an aberrant initial immune response with age. At later time points, inoculation of LPS into the respiratory tract of aged mice was associated with subsequent heightened levels of chemokines CXCL1 and CXCL2, IL-1 $\beta$, and lingering pulmonary neutrophilia at 72 hours in aged animals as compared to young. ${ }^{44}$ Considering the delicate lung alveolar architecture and the highly hydrolytic enzymatic degranulation products of activated neutrophils, this may contribute to excessive tissue damage and reduced lung function over time. 
In addition to age-related perturbations in recruitment following inhalational injury or infectious insult, McLachlan et al examined cytotoxic activity of monocytes in older patients compared to younger patients in response to LPS exposure, and found that older patients display less reactive oxygen species (ROS) ${ }^{54}$ Cytotoxicity generated by the production of ROS and reactive nitrogen intermediates (RNI) is a key function of M1, or proinflammatory macrophages, responsible for activating the Type 1 helper T cells (Th1) pathway. Alteration in macrophage polarization marked by reduced ROS and RNI is reported with advanced age. ${ }^{55}$ Supporting the study by McLachlan et al, alveolar macrophages from aged rats had reduced basal and LPS-activated levels of ROS and RNI. ${ }^{56}$ Our lab and others have also demonstrated that aging is associated with lower levels of inducible nitric oxide synthase (iNOS), an enzyme that regulates production of ROS and RNI under control of the interferon- $\gamma$ receptor. ${ }^{57,58}$ In conjunction with these changes in macrophage phenotype and cytotoxicity, others found that neutrophils from older individuals ( $\geq 85$ years) produced less superoxide. ${ }^{54,59}$ These changes in reactivity have implications for compromising host defenses with age.

In addition to changes in innate system functioning with age, there are changes seen in adaptive immunity with age. In order to activate B- and T cells, dendritic cells (DCs) must migrate from sites of tissue injury and infection to local lymph nodes. Several studies demonstrated DCs from aged mice show poor migration and homing. DC migration in response to chemokine ligand-21, a key DC chemokine that is localized in lymph nodes and binds chemokine receptor type 7 and presents on DC cell membranes, was reduced in aged mice as compared to young. ${ }^{60}$ Interestingly, following respiratory infection in the lungs of aged mice with either mouse hepatitis virus-1, respiratory syncytial virus, influenza A virus, or severe acute respiratory syndrome coronavirus, elevated expression of prostaglandin $\mathrm{D}_{2}$ correlated with reduced homing of lung DCs to regional lymph nodes and T cell activation. ${ }^{61}$ Functional antagonism of prostaglandin $\mathrm{D}_{2}$ resulted in upregulation of chemokine receptor type 7 , the critical receptor for DC migration, and improved DC homing to draining lymph nodes, subsequently improving $\mathrm{T}$ cell activation and survival after viral infection. ${ }^{61}$

There are many adaptive immune functions that are inefficient with age. The thymus is primarily responsible for producing naïve $\mathrm{T}$ cells and is replaced by fatty tissue by age 60 years. ${ }^{62}$ This leads to an increase in memory T cells relative to naïve $\mathrm{T}$ cells ${ }^{63}$ Both naïve $\mathrm{CD} 4+$ and $\mathrm{CD} 8+\mathrm{T}$ cells are reduced in aged animals and humans relative to their memory
T cells counterparts. ${ }^{64-66}$ In regard to CD8+T cells, it has been suggested that repeated or latent cytomegalovirus infection may results in expansion of CD8+ memory cells, again diminishing the naïve CD8+ T cell pool. ${ }^{67}$ Moreover, the proliferative aptitude of $\mathrm{CD} 4+\mathrm{T}$ cells from aged donors appears to be reduced following $\mathrm{T}$ cell receptor engagement with high-dose anti-CD3 antibody in comparison to young controls ${ }^{68}$ suggesting a weaker novel pathogen-specific immune response. Meyer et al looked at the ratio of $\mathrm{CD} 4+$ to $\mathrm{CD} 8+\mathrm{T}$ cells in bronchoalveolar lavage fluid in young versus old normal volunteers and found an increase in $\mathrm{CD} 4+/ \mathrm{CD} 8+$ ratio as a function of age, suggesting there are fewer naïve cells available to be converted to memory cells in the face of a novel infection. ${ }^{69,70}$ Recently, forkhead box N1, a transcription factor known to play a role in embryonic thymus development, has been shown to play a critical role in preventing thymic involution and preservation of naïve $\mathrm{T}$ cell subsets with aging. ${ }^{71}$ Overexpression of forkhead box N1 was demonstrated to increase early thymic progenitors, decrease splenic CD4+ memory $\mathrm{T}$ cells, and increase splenic naïve CD4+ and CD8+ T cells. ${ }^{71}$ These data suggest a possible potential target to increase the number of naïve $T$ cells in aged individuals, increasing the ability of the elderly to respond to novel antigens. The antibody-secreting capacity of B cells is reduced with age, perhaps leading to a less robust immunologic response. ${ }^{72}$

\section{Aging and respiratory disease development}

The prevalence of COPD is two to three times higher in people over age $60 .{ }^{73,74}$ It is projected that from 1990 to 2020 , COPD will move from the sixth to the third leading cause of death worldwide. ${ }^{75}$ The Rotterdam study found that of healthy 55-year-olds without COPD, one in six women and one in four men will develop COPD later in life, with the risk for developing COPD over the coming 40 years being $24 \%$ and $16 \%$, respectively ${ }^{76}$ Cigarette smoking is the greatest risk factor for developing COPD in genetically susceptible individuals. COPD is characterized by airway and lung inflammation, mucociliary dysfunction, alveolar destruction, and airway fibrosis. ${ }^{77}$ The increased burden of COPD seen in the elderly population may be due to age-associated changes in the structure and function of the lung, increasing the pathogenetic susceptibility to COPD. These changes, described in elderly lifelong nonsmokers, are characterized by airspace dilatation resulting from loss of supporting tissue without alveolar wall destruction, similar to changes seen with COPD. ${ }^{77}$ The Global initiative for chronic Obstructive Lung Disease (GOLD) criteria, accepted by the American Thoracic Society and the 
European Respiratory Society, is the standard for the diagnosis and classification of COPD, and is assessed by measuring the ratio of $\mathrm{FEV}_{1}$ to the forced vital capacity $(\mathrm{FVC}) .{ }^{78} \mathrm{FEV}_{1}$ peaks between ages 20-36 years, and then begins to decline as we age. ${ }^{79}$ The annual rate of decline after the age of 25 is $20 \mathrm{~mL}$ per year and further declines to a loss of $38 \mathrm{~mL}$ per year after age $65 .{ }^{79} \mathrm{FVC}$ begins to decline later in life than $\mathrm{FEV}_{1}$ and at a slower pace. Because of the unparalleled rate of decline, use of the $\mathrm{FEV}_{1} / \mathrm{FVC}$ ratio alone to diagnose COPD will over represent a COPD diagnosis when no such pathology may exist. ${ }^{80}$ To complicate this matter, Ohar et al found that COPD is underdiagnosed in the United States, arguing that this is due to underutilization of spirometry as a screening test for COPD. ${ }^{81}$ Therefore, it is recommended to practitioners that a combination of spirometry and symptoms typical of COPD be utilized in the diagnosis of COPD in the elderly.

COPD is often associated with multiple comorbidities which can effect overall severity of disease. These include osteoporosis, mental illness, malnutrition, risk of cardiovascular disease, and skeletal muscle dysfunction. ${ }^{82}$ Low body mass index is commonly seen in patients with COPD and has been shown to be inversely related to mortality in COPD. ${ }^{83,84}$ Anxiety and depression are prevalent comorbidities and have also been shown to be related to negative outcomes in COPD. It is estimated that $40 \%$ of individuals with COPD have depression, compared to a prevalence of $15 \%$ in the general population. ${ }^{85}$ Cognitive impairments are common and associated with COPD in the elderly. It is estimated that anywhere between $42 \%-70 \%$ of aged persons with COPD have concomitant dementia or neurocognitive impairment. ${ }^{86-88}$ This may be related to hypoxemia and hypercapnia associated with COPD. ${ }^{89}$ It may also be due to the common occurrence of cardiovascular disease in elderly with COPD..$^{90}$ These conditions certainly impact the ability to tolerate and comply with prescribed COPD therapies.

Inhaled bronchodilator therapy is the mainstay of treatment for the management of COPD. Treatment options are varied and include metered dose inhaler, dry powder inhaler, or nebulized formulations. There are many factors which may impact effective treatment use in the elderly COPD population including arthritis, weakness, poor manual dexterity, cognitive impairments, and visual limitations. ${ }^{91}$ Careful consideration regarding treatment recommendations must be made in the aging COPD population.

\section{Summary}

There are many age-associated changes in the respiratory and pulmonary system. The size of the thoracic cavity decreases, limiting lung volumes and altering the muscles that aid in respiration. Muscle function on a cellular level is less efficient and has decreased reserve. Cough strength is reduced in the elderly population due to anatomic changes and muscle atrophy. Clearance of particles from the lung through the mucociliary elevator is negatively impacted and associated with ciliary dysfunction. There are many complex changes in immunity with aging that increase susceptibility to infections, including a less robust immune response from both the innate and adaptive immune systems. Finally, COPD has the highest prevalence in the elderly and deserves special consideration in regard to treatment in this fragile population. Additional research is needed to improve our understanding of the determinants of lung aging and the effects on lung immunity.

\section{Disclosure}

The authors report no conflicts of interest in this work.

\section{References}

1. Miniño AM. Death in the United States, 2011. NCHS Data Brief. 2013;115:1-8.

2. Werner CA. Census 2010 Brief C2010BR-09: The Older Population: 2010. Washington, DC: US Department of Commerce; 2011. Available at: http://www.census.gov/prod/cen2010/briefs/c2010br-09.pdf. Accessed May 28, 2013.

3. Bartynski WS, Heller MT, Grahovac SZ, Rothfus WE, Kurs-Lasky M. Severe thoracic kyphosis in the older patient in the absence of vertebral fracture: association of extreme curve with age. AJNR Am J Neuroradiol. 2005;26(8):2077-2085.

4. Sharma G, Goodwin J. Effect of aging on respiratory system physiology and immunology. Clin Interv Aging. 2006;1(3):253-260.

5. Ensrud KE, Black DM, Harris F, Ettinger B, Cummings SR. Correlates of kyphosis in older women. The Fracture Intervention Trial Research Group. J Am Geriatr Soc. 1997;45(6):682-687.

6. Fon GT, Pitt MJ, Thies AC Jr. Thoracic kyphosis: range in normal subjects. AJR Am J Roentgenol. 1980;134(5):979-983.

7. Lombardi I Jr, Oliveira LM, Mayer AF, Jardim JR, Natour J. Evaluation of pulmonary function and quality of life in women with osteoporosis. Osteoporosis Int. 2005;16(10):1247-1253.

8. Culham EG, Jimenez HA, King CE. Thoracic kyphosis, rib mobility, and lung volumes in normal women and women with osteoporosis. Spine. 1994;19(11):1250-1255.

9. Arora NS, Rochester DF. Effect of body weight and muscularity on human diaphragm muscle mass, thickness, and area. J Appl Physiol. 1982;52(1):64-70.

10. Brown M, Hasser EM. Complexity of age-related change in skeletal muscle. J Gerontol A Biol Sci Med Sci. 1996;51(2):B117-B123.

11. Freitas FS, Ibiapina CC, Alvim CG, Britto RR, Parreira VF. Relationship between cough strength and functional level in elderly. Rev Bras Fisioter. 2010;14(6):470-476.

12. Desler C, Hansen TL, Frederiksen JB, Marcker ML, Singh KK, Juel Rasmussen $\mathrm{L}$. Is there a link between mitochondrial reserve respiratory capacity and aging? J Aging Res. 2012;2012: Article ID 192503.

13. Sevransky JE, Haponik EF. Respiratory failure in elderly patients. Clin Geriatr Med. 2003;19(1):205-224.

14. McCool FD. Global physiology and pathophysiology of cough: ACCP evidence-based clinical practice guidelines. Chest. 2006;129(Suppl 1): $48 \mathrm{~S}-53 \mathrm{~S}$. 
15. Hegland KW, Troche MS, Davenport PW. Cough expired volume and airflow rates during sequential induced cough. Front Physiol. 2013;4:167.

16. Kim J, Davenport P, Sapienza C. Effect of expiratory muscle strength training on elderly cough function. Arch Gerontol Geriatr. 2009;48(3): 361-366

17. Polkey MI, Harris ML, Hughes PD, et al. The contractile properties of the elderly human diaphragm. Am J Respir Crit Care Med. 1997;155(5): 1560-1564.

18. Tolep K, Higgins N, Muza S, Criner G, Kelsen SG. Comparison of diaphragm strength between healthy adult elderly and young men. Am J Respir Crit Care Med. 1995;152(2):677-682.

19. Chen HI, Kuo CS. Relationship between respiratory muscle function and age, sex, and other factors. J Appl Physiol. 1989;66(2): 943-948.

20. Berry JK, Vitalo CA, Larson JL, Patel M, Kim MJ. Respiratory muscle strength in older adults. Nurs Res. 1996;45(3):154-159.

21. Faulkner JA, Brooks SV, Zerba E. Skeletal muscle weakness and fatigue in old age: underlying mechanisms. Annu Rev Gerontol Geriatr. 1990;10:147-166

22. Mobasheri A, Mendes AF. Physiology and pathophysiology of musculoskeletal aging: current research trends and future priorities. Front Physiol. 2013;4:73.

23. Wanner A. Clinical aspects of mucociliary transport. Am Rev Respir Dis. 1977;116(1):73-125.

24. Chilvers MA, O’Callaghan C. Local mucociliary defence mechanisms. Paediatr Respir Rev. 2000;1(1):27-34.

25. de Oliveira-Maul JP, de Carvalho HB, Miyuki Goto D, et al. Aging, diabetes, and hypertension are associated with decreased nasal mucociliary clearance. Chest. 2013;143(4):1091-1097.

26. Svartengren M, Falk R, Philipson K. Long-term clearance from small airways decreases with age. Eur Respir J. 2005;26(4):609-615.

27. Agius AM, Smallman LA, Pahor AL. Age, smoking and nasal ciliary beat frequency. Clin Otolaryngol Allied Sci. 1998;23(3):227-230.

28. Panda A, Arjona A, Sapey E, et al. Human innate immunosenescence: causes and consequences for immunity in old age. Trends Immunol. 2009;30(7):325-333.

29. Kovacs EJ, Grabowski KA, Duffner LA, Plackett TP, Gregory MS Survival and cell mediated immunity after burn injury in aged mice. J Am Aging Assoc. 2002;25(1):3-9.

30. Gomez CR, Nomellini V, Baila H, Oshima K, Kovacs EJ. Comparison of the effects of aging and IL-6 on the hepatic inflammatory response in two models of systemic injury: scald injury versus i.p. LPS administration. Shock. 2009;31(2):178-184.

31. Gómez CR, Acuña-Castillo C, Nishimura S, et al. Serum from aged F344 rats conditions the activation of young macrophages. Mech Ageing Dev. 2006;127(3):257-263.

32. Ershler WB, Keller ET. Age-associated increased interleukin-6 gene expression, late-life diseases, and frailty. Annu Rev Med. 2000;51: 245-270.

33. Ren Z, Gay R, Thomas A, et al. Effect of age on susceptibility to Salmonella Typhimurium infection in C57BL/6 mice. J Med Microbiol. 2009;58(Pt 12):1559-1567.

34. Murciano C, Yáñez A, O’Connor JE, Gozalbo D, Gil ML. Influence of aging on murine neutrophil and macrophage function against Candida albicans. FEMS Immunol Med Microbiol. 2008;53(2):214-221.

35. Shaik-Dasthagirisaheb YB, Kantarci A, Gibson FC. Immune response of macrophages from young and aged mice to the oral pathogenic bacterium Porphyromonas gingivalis. Immun Ageing. 2010;7:15.

36. Murciano C, Villamón E, Yáñez A, O’Connor JE, Gozalbo D, Gil ML. Impaired immune response to Candida albicans in aged mice. $\mathrm{J} \mathrm{Med}$ Microbiol. 2006;55(Pt 12):1649-1656.

37. van Duin D, Mohanty S, Thomas V, et al. Age-associated defect in human TLR-1/2 function. J Immunol. 2007;178(2):970-975.

38. Chelvarajan RL, Liu Y, Popa D, et al. Molecular basis of age-associated cytokine dysregulation in LPS-stimulated macrophages. J Leukoc Biol. 2006;79(6):1314-1327.
39. Gomez CR, Goral J, Ramirez L, Kopf M, Kovacs EJ. Aberrant acute-phase response in aged interleukin-6 knockout mice. Shock. 2006;25(6):581-585.

40. Gomez CR, Karavitis J, Palmer JL, et al. Interleukin-6 contributes to age-related alteration of cytokine production by macrophages. Mediators Inflamm. 2010;2010:475139.

41. Olivieri F, Rippo MR, Monsurro V, et al. MicroRNAs linking inflamm-aging, cellular senescence and cancer. Ageing Res Rev. Epub May 17, 2013

42. Olivieri F, Lazzarini R, Recchioni R, et al. MiR-146a as marker of senescence-associated pro-inflammatory status in cells involved in vascular remodelling. Age (Dordr). 2013;35(4):1157-1172.

43. Mares CA, Ojeda SS, Li Q, Morris EG, Coalson JJ, Teale JM. Aged mice display an altered pulmonary host response to Francisella tularensis live vaccine strain (LVS) infections. Exp Gerontol. 2010;45(2):91-96.

44. Ito Y, Betsuyaku T, Nasuhara Y, Nishimura M. Lipopolysaccharideinduced neutrophilic inflammation in the lungs differs with age. Exp Lung Res. 2007;33(7):375-384.

45. Bruunsgaard H, Andersen-Ranberg K, Hjelmborg Jv, Pedersen BK, Jeune B. Elevated levels of tumor necrosis factor alpha and mortality in centenarians. Am J Med. 2003;115(4):278-283.

46. Caruso C, Lio D, Cavallone L, Franceschi C. Aging, longevity, inflammation, and cancer. Ann N Y Acad Sci. 2004;1028:1-13.

47. Turrentine FE, Wang H, Simpson VB, Jones RS. Surgical risk factors, morbidity, and mortality in elderly patients. J Am Coll Surg. 2006;203(6):865-877.

48. Butcher SK, Killampalli V, Chahal H, Kaya Alpar E, Lord JM. Effect of age on susceptibility to post-traumatic infection in the elderly. Biochem Soc Trans. 2003;31(2):449-451.

49. Renshaw M, Rockwell J, Engleman C, Gewirtz A, Katz J, Sambhara S. Cutting edge: impaired Toll-like receptor expression and function in aging. J Immunol. 2002;169(9):4697-4701.

50. Chelvarajan RL, Collins SM, Van Willigen JM, Bondada S. The unresponsiveness of aged mice to polysaccharide antigens is a result of a defect in macrophage function. J Leukoc Biol. 2005;77(4):503-512.

51. Boehmer ED, Meehan MJ, Cutro BT, Kovacs EJ. Aging negatively skews macrophage TLR2- and TLR4-mediated pro-inflammatory responses without affecting the IL-2-stimulated pathway. Mech Ageing Dev. 2005;126(12):1305-1313.

52. Moriyama C, Betsuyaku T, Ito Y, et al. Aging enhances susceptibility to cigarette smoke-induced inflammation through bronchiolar chemokines. Am J Respir Cell Mol Biol. 2010;42(3):304-311.

53. Sunil VR, Patel KJ, Mainelis G, et al. Pulmonary effects of inhaled diesel exhaust in aged mice. Toxicol Appl Pharmacol. 2009;241(3):283-293.

54. McLachlan JA, Serkin CD, Morrey KM, Bakouche O. Antitumoral properties of aged human monocytes. J Immunol. 1995;154(2):832-843.

55. Dace DS, Apte RS. Effect of senescence on macrophage polarization and angiogenesis. Rejuvenation Res. 2008;11(1):177-185.

56. Tasat DR, Mancuso R, O'Connor S, Molinari B. Age-dependent change in reactive oxygen species and nitric oxide generation by rat alveolar macrophages. Aging cell. 2003;2(3):159-164.

57. Kissin E, Tomasi M, McCartney-Francis N, Gibbs CL, Smith PD. Age-related decline in murine macrophage production of nitric oxide. J Infect Dis. 1997;175(4):1004-1007.

58. Ding A, Hwang S, Schwab R. Effect of aging on murine macrophages. Diminished response to IFN-gamma for enhanced oxidative metabolism. J Immunol. 1994;153(5):2146-2152.

59. Polignano A, Tortorella C, Venezia A, Jirillo E, Antonaci S. Ageassociated changes of neutrophil responsiveness in a human healthy elderly population. Cytobios. 1994;80(322):145-153.

60. Grolleau-Julius A, Harning EK, Abernathy LM, Yung RL. Impaired dendritic cell function in aging leads to defective antitumor immunity. Cancer Res. 2008;68(15):6341-6349.

61. Zhao J, Zhao J, Legge K, Perlman S. Age-related increases in PGD(2) expression impair respiratory DC migration, resulting in diminished T cell responses upon respiratory virus infection in mice. J Clin Invest. 2011;121(12):4921-4930. 
62. Gruver AL, Hudson LL, Sempowski GD. Immunosenescence of ageing. J Pathol. 2007;211(2):144-156.

63. Timm JA, Thoman ML. Maturation of CD4+ lymphocytes in the aged microenvironment results in a memory-enriched population. J Immunol. 1999;162(2):711-717.

64. Posnett DN, Sinha R, Kabak S, Russo C. Clonal populations of T-cells in normal elderly humans: the T-cell equivalent to "benign monoclonal gammapathy". J Exp Med. 1994;179(2):609-618.

65. Hong MS, Dan JM, Choi JY, Kang I. Age-associated changes in the frequency of naïve, memory and effector CD8+ T-cells. Mech Ageing Dev. 2004;125(9):615-618.

66. Provinciali M, Moresi R, Donnini A, Lisa RM. Reference values for CD4+ and CD8+ T lymphocytes with naïve or memory phenotype and their association with mortality in the elderly. Gerontology. 2009;55(3): 314-321.

67. Khan N, Shariff N, Cobbold M, et al. Cytomegalovirus seropositivity drives the CD8 T-cell repertoire toward greater clonality in healthy elderly individuals. J Immunol. 2002;169(4):1984-1992.

68. Mirza N, Pollock K, Hoelzinger DB, Dominguez AL, Lustgarten J. Comparative kinetic analyses of gene profiles of naive CD4+ and CD8+ T-cells from young and old animals reveal novel age-related alterations. Aging Cell. 2011;10(5):853-867.

69. Franceschi C, Bonafè M, Valensin S. Human immunosenescence: the prevailing of innate immunity, the failing of clonotypic immunity, and the filling of immunological space. Vaccine. 2000;18(16):1717-1720.

70. Meyer KC, Ershler W, Rosenthal NS, Lu XG, Peterson K. Immune dysregulation in the aging human lung. Am J Respir Crit Care Med. 1996;153(3):1072-1079.

71. Zook EC, Krishack PA, Zhang S, et al. Overexpression of Foxn1 attenuates age-associated thymic involution and prevents the expansion of peripheral CD4 memory T-cells. Blood. 2011;118(22):5723-5731.

72. Song H, Price PW, Cerny J. Age-related changes in antibody repertoire: contribution from T-cells. Immunol Rev. 1997;160:55-62.

73. Buist AS, McBurnie MA, Vollmer WM, et al; BOLD Collaborative Research Group. International variation in the prevalence of COPD (the BOLD Study): a population-based prevalence study. Lancet. 2007;370(9589):741-750.

74. Fukuchi Y, Nishimura M, Ichinose M, et al. COPD in Japan: the Nippon COPD Epidemiology study. Respirology. 2004;9(4):458-465.

75. Murray CJ, Lopez AD. Alternative projections of mortality and disability by cause 1990-2020: Global Burden of Disease Study. Lancet. 1997;349(9064):1498-1504.

76. van Durme YM, Verhamme KM, Stijnen T, et al. Prevalence, incidence, and lifetime risk for the development of COPD in the elderly: the Rotterdam study. Chest. 2009;135(2):368-377.
77. Sharma G, Hanania NA, Shim YM. The aging immune system and its relationship to the development of chronic obstructive pulmonary disease. Proc Am Thorac Soc. 2009;6(7):573-580.

78. Rabe KF, Hurd S, Anzueto A, et al; Global Initiative for Chronic Obstructive Lung Disease. Global strategy for the diagnosis, management, and prevention of chronic obstructive pulmonary disease: GOLD executive summary. Am J Respir Crit Care Med. 2007;176(6):532-555.

79. Brandstetter RD, Kazemi H. Aging and the respiratory system. Med Clin North Am. 1983;67(2):419-431.

80. Dyer C. The interaction of ageing and lung disease. Chron Respir Dis. 2012;9(1):63-67.

81. Ohar JA, Sadeghnejad A, Meyers DA, Donohue JF, Bleecker ER. Do symptoms predict COPD in smokers? Chest. 2010;137(6): 1345-1353.

82. Agusti A, Soriano JB. COPD as a systemic disease. COPD. 2008;5(2): 133-138.

83. Pauwels RA, Buist AS, Calverley PM, Jenkins CR, Hurd SS; GOLD Scientific Committee. Global strategy for the diagnosis, management, and prevention of chronic obstructive pulmonary disease. NHLBI/ WHO Global Initiative for Chronic Obstructive Lung Disease (GOLD) Workshop summary. Am J Respir Crit Care Med. 2001;163(5): 1256-1276.

84. Landbo C, Prescott E, Lange P, Vestbo J, Almdal TP. Prognostic value of nutritional status in chronic obstructive pulmonary disease. Am J Respir Crit Care Med. 1999;160(6):1856-1861.

85. Norwood RJ. A review of etiologies of depression in COPD. Int J Chron Obstruct Pulmon Dis. 2007;2(4):485-491.

86. Petty TL, Bliss PL. Ambulatory oxygen therapy, exercise, and survival with advanced chronic obstructive pulmonary disease (the Nocturnal Oxygen Therapy Trial revisited). Respir Care. 2000;45(2):204-211; discussion 211-213.

87. Grant I, Heaton RK, McSweeny AJ, Adams KM, Timms RM. Neuropsychologic findings in hypoxemic chronic obstructive pulmonary disease. Arch Intern Med. 1982;142(8):1470-1476.

88. Hung WW, Wisnivesky JP, Siu AL, Ross JS. Cognitive decline among patients with chronic obstructive pulmonary disease. Am J Respir Crit Care Med. 2009;180(2):134-137.

89. Kirkil G, Tug T, Ozel E, Bulut S, Tekatas A, Muz MH. The evaluation of cognitive functions with P300 test for chronic obstructive pulmonary disease patients in attack and stable period. Clin Neurol Neurosurg. 2007;109(7):553-560.

90. Fillit H, Nash DT, Rundek T, Zuckerman A. Cardiovascular risk factors and dementia. Am J Geriatr Pharmacother. 2008;6(2):100-118.

91. Armitage JM, Williams SJ. Inhaler technique in the elderly. Age Ageing. 1988;17(4):275-278.
Clinical Interventions in Aging

\section{Publish your work in this journal}

Clinical Interventions in Aging is an international, peer-reviewed journa focusing on evidence-based reports on the value or lack thereof of treatments intended to prevent or delay the onset of maladaptive correlates of aging in human beings. This journal is indexed on PubMed Central, MedLine, the American Chemical Society's 'Chemical Abstracts
Dovepress

Service' (CAS), Scopus and the Elsevier Bibliographic databases. The manuscript management system is completely online and includes a very quick and fair peer-review system, which is all easy to use. Visit http://www.dovepress.com/testimonials.php to read real quotes from published authors. 